This is a postprint version of the following published document:

Pernas-Sánchez, J., Artero-Guerrero, J.A., Zahr, J., Varas, D., \& López-Puente, J. (2014). Numerical analysis of high velocity impacts on unidirectional laminates. Composite Structures, v. 107, pp. 629-634.

DOI: 10.1016/j.compstruct.2013.08.035

Proyectos:

DPI2010-15123

CCG10-UC3M/DPI-4694

(C) Elsevier 2014

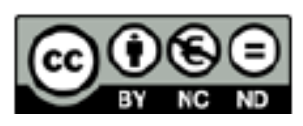

This work is licensed under a Creative Commons Attribution-NonCommercialNoDerivatives 4.0 International License. 


\title{
Numerical analysis of high velocity impacts on unidirectional laminates
}

\author{
J. Pernas-Sánchez, J.A. Artero-Guerrero, J. Zahr Viñuela, \\ D. Varas, J. López-Puente * \\ Department of Continuum Mechanics and Structural Analysis. University Carlos \\ III of Madrid. Avda. de la Universidad, 30. 28911 Leganés, Madrid, Spain
}

\begin{abstract}
In this work a numerical methodology to predict the behavior of composite unidirectional laminates under high velocity impact is developed. In order to validate the model, experimental results of high velocity impacts of steel sphere against laminate coupons, were accomplished. The residual velocity in case of penetration and the damaged area in the panel are the variables chosen to validate the results obtained in the numerical methodology proposed. Finally an analysis of the influence of the projectile geometry is accomplished.
\end{abstract}

Key words: carbon, epoxy, impact, high velocity, unidirectional.

* Corresponding author. Fax number: 34 916248331. E-mail address: jlpuente@ing.uc3m.es 


\section{Introduction}

One of the main requirements in the aeronautical industry regarding structural design is to keep weight of structural components as low as possible for any given structural requirement, often specified in terms of displacement or strength, and fulfilling some criteria for tolerance to damage. These requirements have propelled in the last decades the use of composite materials, particularly CFRP unidirectional laminates. In this context, the structural problem of high velocity impact of debris on aircraft components of composite materials has become a subject of intense interest [1-16], not only from the point of view of experimental research [17-19] but also from the perspective of numerical simulation and virtual testing, given its potential for reducing the total cost of development of aeronautic structures [20-26]. These computational aspects are the subject of the present work, which deals with the development of a numerical methodology able to faithfully reproduce the behavior of carbon/epoxy laminates under high velocity impact of small debris.

Regarding numerical modeling of impact phenomena, research has focused on various subjects such as building or improving beam and shell theory and, particularly, on the development of constitutive and damage models for composite materials. Of the latter, a large number of models can be found in the literature, which can be roughly classified in two categories: discrete (or uncoupled) models and models of Continuum Damage Mechanics (CDM).

Mechanical loading of structural elements of thin, planar topology made of laminated composite materials are often modeled by means of Finite Elements. As thickness is small as compared with overall size of these planar 
elements, a single layered shell element is used through the thickness, with each layer characterized by an orthotropic, linear elastic constitutive behavior. If damage is to be modeled using discrete models, the behavior of each layer is considered linear elastic up to the point in which a failure criterion is satisfied, a point after which the element loses its stress carrying capacity. Several discrete damage models have been used as failure criteria for layered shell elements representing a laminated composite $[27,28]$. The most used among these are maximum stress or strain criteria, Hashin [29], Chang-Chang [30] and Hou et al. [31], or modifications of those models [12]. Aforementioned models usually involve differentiated damage parameters for one or more of the known failure modes for laminates, such as fiber breaking in tension, fiber buckling in compression, matrix cracking, fiber-matrix debonding or delamination of the composites plies. The damage parameters, however, do not participate in the constitutive model as an internal variable, hence their qualification of uncoupled models. If, on the other hand, damage is to be modeled using CDM type, damage parameters for the different failure modes are considered as internal variables of the whole constitutive behavior of the composite material, thus modeling the coupling between strain and damage in a more or less progressive way. In some cases, homogenization theory is used to represent the composite material as an equivalent homogeneous material whose constitutive behavior is orthotropic and nonlinear because of the damage coupling. Among these models of the CDM type, it is possible to mention LaRC04 [32] and Martinez et. al. [33,34]. As computing power has increased dramatically in recent years, restrictions in mesh density have become less important. As a result, Finite Element modeling of composite laminates using solid elements rather than a single through-thickness layered shell element has turned into a possibility. With this method, it is possible to assign failure criteria related to the fibers 
and to the matrix of these layers of solid elements, while the interlaminar debonding could be modeled using either cohesive elements or cohesive interactions between surfaces. In the present work, such modeling approach is used to model the impact of small metallic projectiles against a planar CFRP laminate.

The objective of this work is to develop a numerical methodology capable to predict the damage caused by the high velocity impact of a projectile on an unidirectional carbon/epoxy laminate. In order to validate the model, experimental tests were accomplished in a wide range of impact velocities; both residual velocity in case of perforation and damaged area were used to validate the proposed methodology. Finally, an analysis of the influence of the projectile sphere radius is performed; the results obtained are explained by means of a simple analytical model.

\section{Numerical model}

The numerical methodology that is going to be presented in the following sections has been implemented using the commercial explicit finite element software LS-DYNA v.R7.

\subsection{Material modeling}

In this section the material modelling for both the projectile and the laminate is presented. The projectile used in the experiments (that are going to be presented later) was made of tempered steel, and due to its strength no plastic deformation has been observed after the impacts. For this reason a linear 
elastic behavior was chosen for the simulations, with the following properties: $E=210 G P a, \nu=0.3$ and $\rho=7850 \mathrm{~kg} / \mathrm{m}^{3}$.

The carbon/epoxy unidirectional plies have been modelled using an orthotropic linear elastic behavior until failure, which was modelled using the ChangChang [30] criteria; this model adequately predicts the different damage mechanisms that appear intra-laminar. To model the interaction between the laminas, a cohesive interaction approach has been used to take into account the inter-laminar behaviour. This mix-model between material model and cohesive interaction (available in the LS-DYNA library) has been used previously by others authors [35-37]. Following, the different failure modes and the cohesive interaction is described.

\subsubsection{Intra-laminar failure}

The plies behave as an orthotropic elastic material (table 1 shows the elastic properties) until failure; to model it, four different stress based damage criteria are defined, which represents tension and compression failures for the fiber and the matrix. A detailed explanation of the mechanisms is presented:

- Fiber failure under tension: this damage mechanism follows the equation:

$$
e_{f, t}^{2}=\left(\frac{\sigma_{11}}{X_{t}}\right)^{2}+\alpha\left(\frac{\sigma_{12}}{S_{12}}\right)^{2}-1
$$

where $\sigma_{i j}$ are the stress tensor components, and $X_{t}$ and $S_{12}$ are the strengths of the composite laminate in tension (in the fiber direction) and under in-plane shear respectively. The parameter $\alpha$ allows to calibrate the shear stress interaction, in order to not overestimate its contribution as the Hashin criterion does (it assumes $\alpha=1$ ); the parameter must be less than 1 and 
positive.

- Fiber failure under compression: in this case the equation is:

$$
e_{f, c}^{2}=\left(\frac{\sigma_{11}}{X_{c}}\right)^{2}-1
$$

where $X_{c}$ is the strength of the laminate in the fiber direction under compression.

- Matrix failure under tension: the equation related to this damage mechanism is:

$$
e_{m, t}^{2}=\left(\frac{\sigma_{22}}{Y_{t}}\right)^{2}+\left(\frac{\sigma_{12}}{S_{12}}\right)^{2}-1
$$

where $Y_{t}$ is the laminate strength under tension in the direction perpendicular to the fibers.

- Matrix failure under compression: its corresponding equation is:

$$
e_{m, c}^{2}=\left(\frac{\sigma_{22}}{2 S_{12}}\right)^{2}+\frac{\sigma_{22}}{Y_{c}}\left(\frac{Y_{c}^{2}}{4 S_{12}^{2}}-1\right)^{2}+\left(\frac{\sigma_{12}}{S_{12}}\right)^{2}-1
$$

When the parameter associated with each failure criteria $\left(e_{i, j}^{2}\right.$ eq. $\left.1,2,3,4\right)$ reaches the value of zero, the stiffness of the element is reduced in the corresponding direction keeping constant the associated stress component. This behavior is based on the theory and experimental results of Hahn and Tsai [38]. Finally when the critical failure strain is reached the element is removed from the simulation.

\subsubsection{Inter-laminar failure}

The inter-laminar failure or delamination plays a minor role in energy absorption mechanisms when subjected to high velocities impacts, but a significant role in the strength after impact of the laminate. In order to model it, a cohesive interaction is used defined by a damage onset law and a damage evolution 


\begin{tabular}{cccccc}
\hline \hline$\rho$ & $E_{1}$ & $E_{2}=E_{3}$ & $G_{12}$ & $G_{23}=G_{31}$ & $\nu_{12}$ \\
$1580 \mathrm{~kg} / \mathrm{m}^{3}$ & $139 \mathrm{GPa}$ & $9 \mathrm{GPa}$ & $5 \mathrm{GPa}$ & $4.5 \mathrm{GPa}$ & 0.3089 \\
\hline$X_{c}$ & $X_{t}$ & $Y_{c}$ & $Y_{t}$ & $S_{c}$ & $\alpha$ \\
$1656 \mathrm{MPa}$ & $2105 \mathrm{MPa}$ & $175 \mathrm{MPa}$ & $79 \mathrm{MPa}$ & $114 \mathrm{MPa}$ & 0.04 \\
\hline$\varepsilon_{1}$ & $\varepsilon_{2}=\varepsilon_{3}$ & $\varepsilon_{12}=\varepsilon_{23}=\varepsilon_{31}$ & $\overline{\varepsilon_{f}}$ & & \\
0.025 & 0.03 & 0.1 & 0.1 & & \\
\hline \hline
\end{tabular}

Table 1

Properties of tape carbon/epoxi laminate provided by the composite manufacturer. law. As it can be seen in Eqs. 5 and 6, both laws are expressed in terms of traction and separation $(\delta)$.

The relative displacement $\delta_{m}=\sqrt{\delta_{I}^{2}+\delta_{I I}^{2}}$ between the surfaces is determined as a function of the displacement in mode I $\left(\delta_{I}=\delta_{3}\right)$ and II $\left(\delta_{I I}=\sqrt{\delta_{1}^{2}+\delta_{2}^{2}}\right)$. When the relative displacement is equal to the mixed mode damage onset displacement $\left(\delta^{0}\right.$, expressed as eq. 5$)$ the maximum traction is reached.

$$
\delta^{0}=\frac{T S}{E_{T} E_{N}} \sqrt{\frac{1+\gamma^{2}}{\left(\frac{S}{E_{T}}\right)^{2}+\left(\beta \frac{T}{E_{N}}\right)^{2}}}
$$

In this equation $T$ and $S$ are the peak traction in normal and tangential direction, respectively; $E_{N}$ and $E_{T}$ are the stiffnesses in normal and tangential direction, respectively; and $\beta$ is the ratio between displacement in mode II and I $\left(\beta=\delta_{I I} / \delta_{I}\right)$.

The damage evolution law is a power law based on energies, in which the ultimate displacement $\left(\delta^{F}\right)$ is defined as: 


\begin{tabular}{cccccc}
\hline \hline$E_{N}=E_{T}$ & $T$ & $S$ & $\mu$ & $G_{I C}$ & $G_{I I C}$ \\
& & & & & \\
$1 \mathrm{Gpa} / \mathrm{mm}$ & $50 \mathrm{MPa}$ & $56 \mathrm{MPa}$ & 1.45 & $250 \mathrm{~J} / \mathrm{m}^{2}$ & $750 \mathrm{~J} / \mathrm{m}^{2}$
\end{tabular}

Table 2

Parameters for the cohesive interaction.

$$
\delta^{F}=\frac{2(1+\beta)^{2}}{\delta^{0}}\left[\left(\frac{E_{N}}{G_{I C}}\right)^{\mu}+\left(\frac{E_{T} \cdot \beta^{2}}{G_{I I C}}\right)^{\mu}\right]^{-\frac{1}{\mu}}
$$

where $G_{I C}$ and $G_{I I C}$ are the energy release rates for mode I and II, and $\mu$ is the power law parameter. The properties that have been used are shown in table 2 .

\subsection{Finite element model}

The composite tape laminate used in the experiments (that will be presented in the next section) consist of 12 unidirectional carbon/epoxy plies, that were modelled by 3D solid hexahedral elements with hourglass control and reduced integration. In through thickness direction, one element per layer is chosen, to capture faithfully the three-dimensional stress state generated in the laminate due to the perpendicular impact. As it was said before, inter-laminar failure is modelled by means of a cohesive interaction which was inserted between every layer. Finally, 270.000 elements are used for the laminate and 11 cohesive interactions. To model the projectile 875 , 3D solid hexahedral elements with hourglass control and reduced integration are used. To reproduce the experimental boundary conditions, the external edge of the laminates was pinned. 


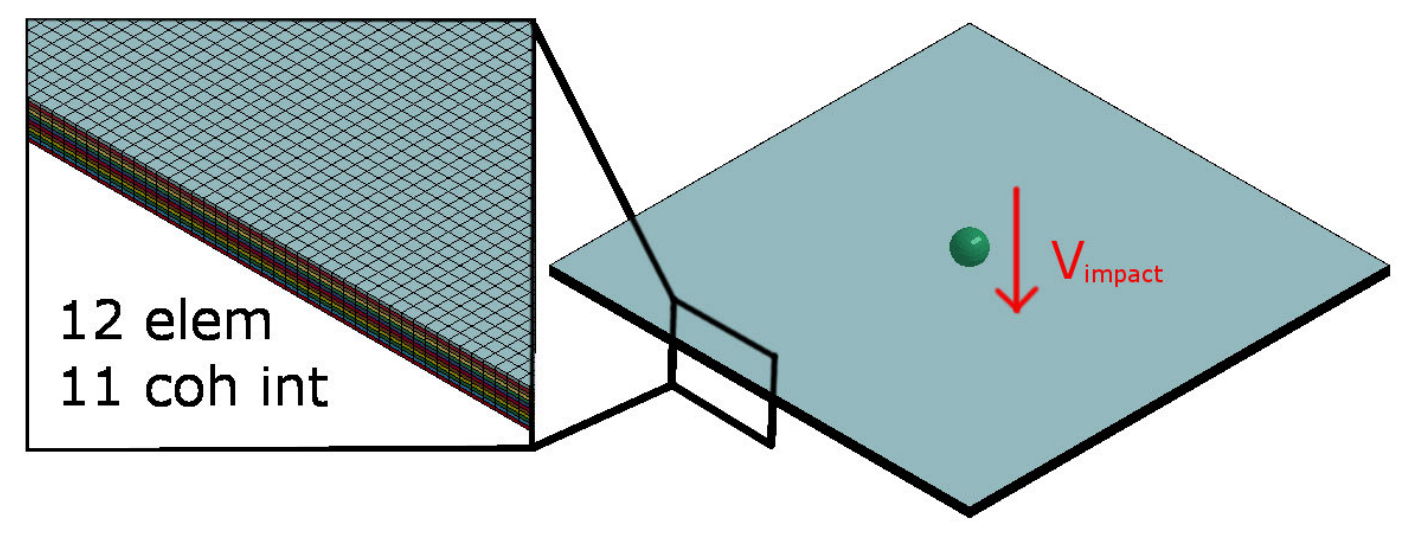

Fig. 1. Lagrangian mesh model and detail of the laminate thickness.

\section{Model validation}

\subsection{Experimental procedure}

Experimental test were accomplished to validate the numerical model proposed in this work. The impacted laminates were manufactured from prepregs made by Hexcel Composites, using AS4 carbon fiber and 8552 epoxy matrix; the ply sequence was $(+45 /-45 / 0 / 90 / 90 / 0)$ s, which leads to a $2.4 \mathrm{~mm}$ thickness. The plates manufactured have been cut to obtain $110 \times 110 \mathrm{~mm}^{2}$ specimens; this size is large enough to avoid that the damage induced during the impact reaches the laminate contour. A steel sphere of $7.5 \mathrm{~mm}$ of diameter has been used as projectile; its hardness was high enough to assure that no plastic deformation appears during the penetration. The projectiles were accelerated using a pneumatic launcher device which uses helium as impeller. Tests were performed in a wide range of impact velocities from 60 to $500 \mathrm{~m} / \mathrm{s}$.

Two variables were selected to validate the numerical model, the residual velocity of the projectile in case of penetration and the damaged area. The first one was measured by means of a high speed video camera, which was set 
to obtain 36000 images per second. The second one was quantified using the ultrasonic C-Scan technique, which allows to accurately measure the projected damaged area in the impacted laminate.

\subsection{Correlation between numerical and experimental results}

In order to validate the numerical model implemented in this work, the numerical simulations have been compared with the experimental tests. As aforementioned two validation variables are used, the projectile residual velocity and the laminate delaminated area. In Fig. 2, it is represented the numerical and experimental residual velocity against the impact velocity. It is observed how the numerical model reproduces faithfully the energy lost by the projectile. In addition, the numerical model predicts accurately the ballistic limit, which is approximately $120 \mathrm{~m} / \mathrm{s}$.

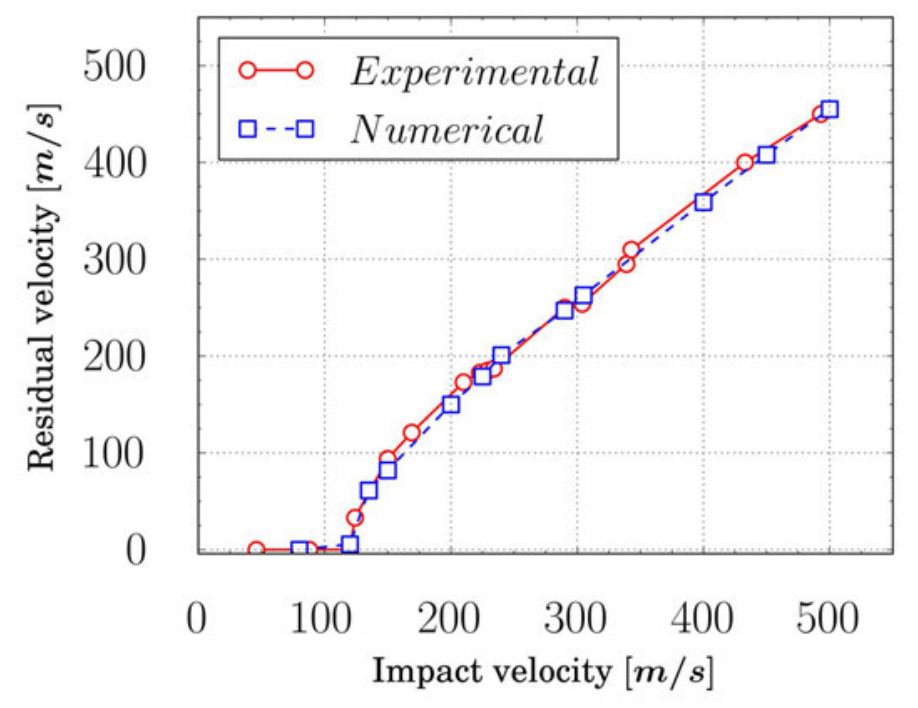

Fig. 2. Residual velocity vs. impact velocity for experimental and numerical impacts.

Fig. 3, compares the numerical and the experimental delaminated area. Although some differences are observed, the numerical model and the experimen- 
tal test show the same trend. At low velocities the delaminated area grows as the impact velocity increases; this behavior changes when the impact velocity reaches approximately $150 \mathrm{~m} / \mathrm{s}$, slightly above the ballistic limit. Above this value the delaminated area diminishes tending asymptotically to a value which corresponds to the projected area of the projectile. Similar results were found in previous works for woven laminates $[12,16]$.

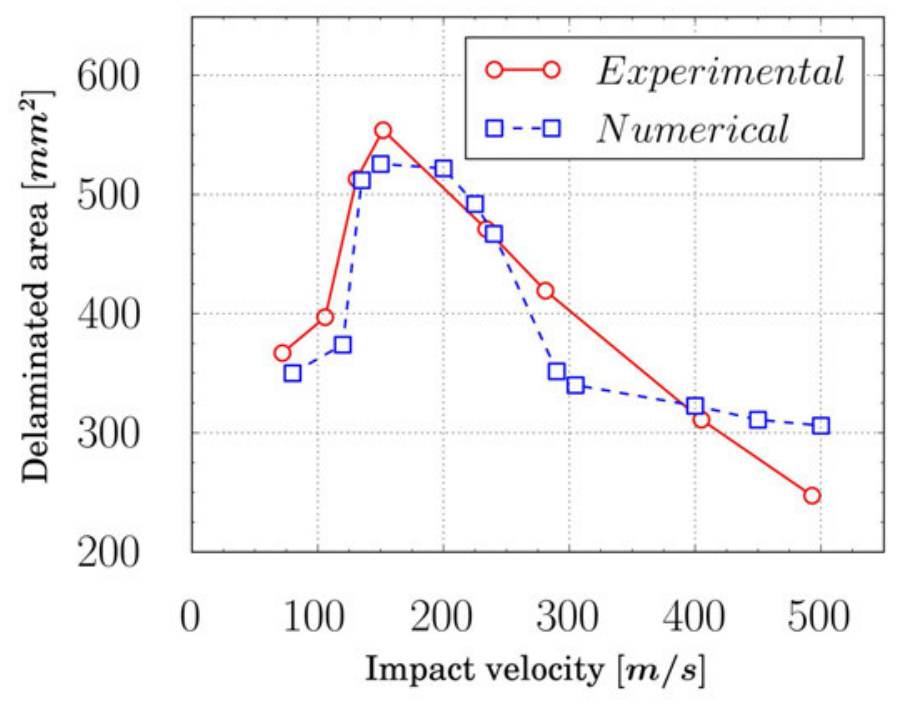

Fig. 3. Damaged area vs. impact velocity for experimental and numerical impacts.

Fig. 4 shows the comparison between the C-Scan images and the damaged area representations obtained in the numerical simulations; it is clear that not only the values of the area are similar, but also the shape of the projected delaminated area.

\section{Analysis of the influence of the projectile radius}

Once the numerical model has been validated, it is possible to use the methodology just described to analyze the influence of the projectile diameter. To this end numerical simulations of high velocity impacts of projectiles with diame- 


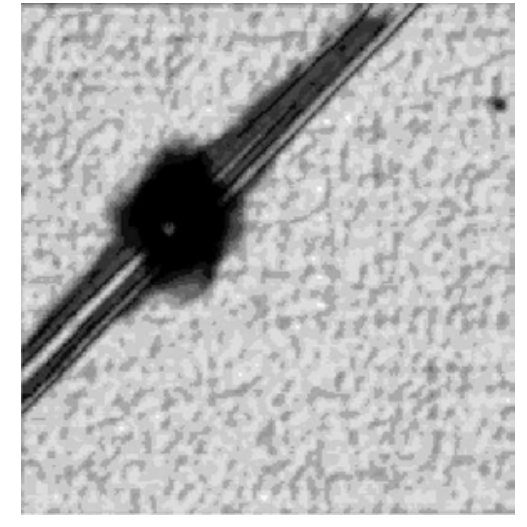

(a) $135 \mathrm{~m} / \mathrm{s}$ Experimental

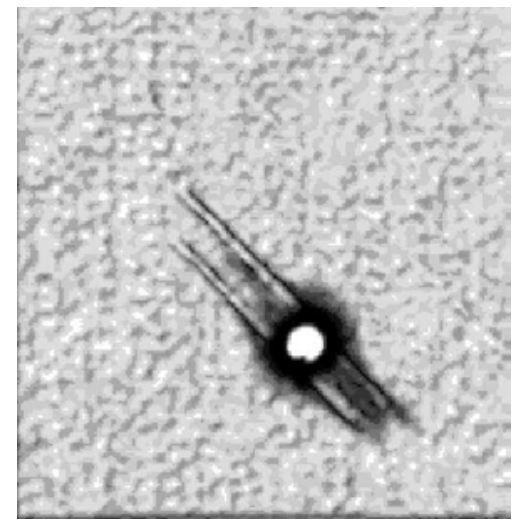

(c) $500 \mathrm{~m} / \mathrm{s}$ Experimental

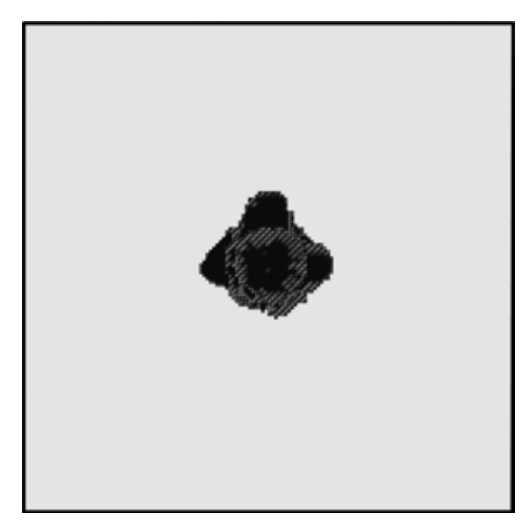

(b) $135 \mathrm{~m} / \mathrm{s}$ Numerical

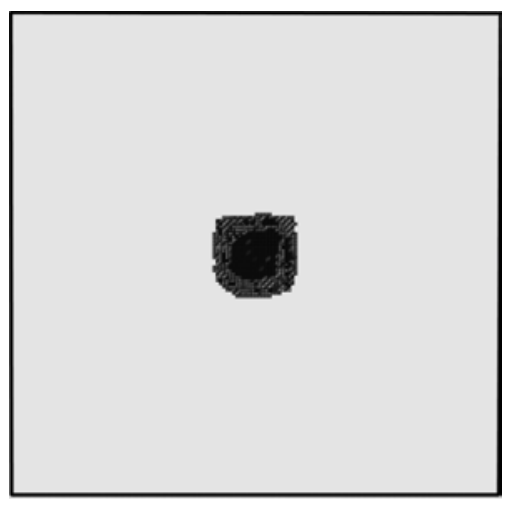

(d) $500 \mathrm{~m} / \mathrm{s}$ Numerical

Fig. 4. Delaminated area for numerical simulations and experimental C-SCAN inspections

ters of 5, 10 and $12.5 \mathrm{~mm}$ (radius of 2.5, 5 and $6.25 \mathrm{~mm}$ ) where accomplished. The laminate characteristics were kept the same as the aforementioned. Fig. 5 shows curves of residual velocity vs. impact velocity for the four diameters analyzed; it is clear from the results that for a given impact velocity, as soon as the radius increases the residual velocity increases also.

This result is not obvious, since there is a competition between two effects. By one side when the projectile diameter increases, the mass also increases (it is $\propto r^{3}$ ), promoting a higher penetration capacity; by the other, when the projectile diameter increases the frontal area increases (it is $\propto r^{2}$ ) diminishing 


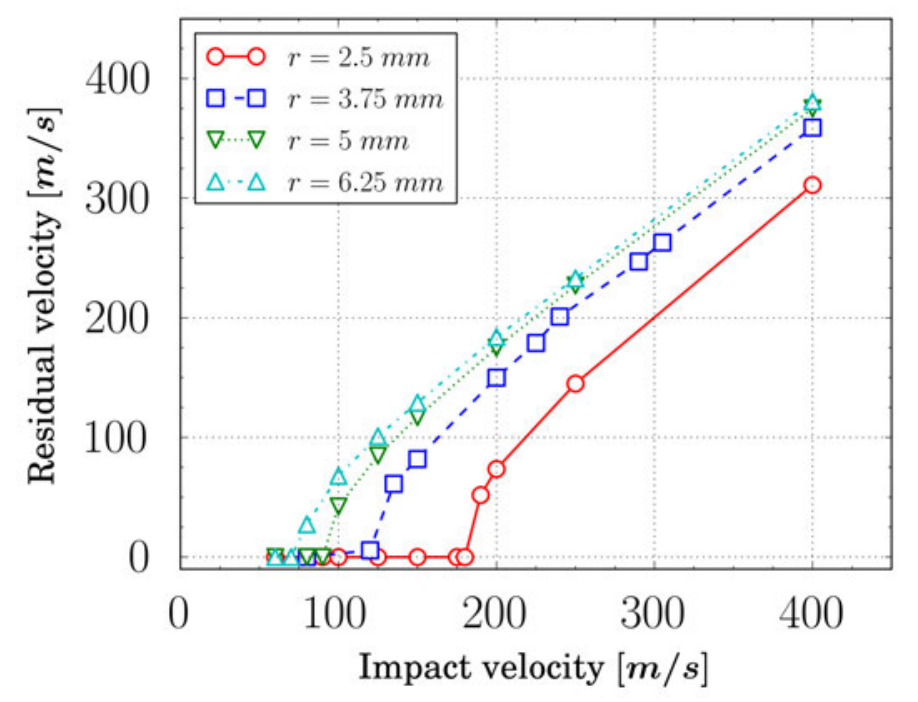

Fig. 5. Residual velocity vs. impact velocity for different projectile radius. the penetration capacity.

In order to understand the result obtained a simple balance of energy is going to be used. In this balance it is assumed that the loss of kinetic energy of the projectile $E_{k}$ is absorbed by the laminate through two mechanisms, plug formation $E_{p}$ and linear momentum transfer $E_{l m}$; other mechanisms such delamination and elastic deformation could be neglected as first approach $[10,14]$. Each term of the energy balance could be analyzed:

- loss of kinetic energy of the projectile: this term can be expressed as $1 / 2 m_{p}\left(v_{i}^{2}-v_{r}^{2}\right)$ where $m_{p}$ is the projectile mass $\left(4 / 3 \pi r^{3} \rho_{s}\right.$ being $r$ the radius and $\rho_{s}$ the density of the steel), $v_{i}$ the impact velocity and $v_{r}$ the residual velocity.

- plug formation: in order to estimate this term it is assumed that the force needed to form the plug is equal to the through thickness shear strength $\tau_{l}$ multiplied by the area involved $2 \pi r h$; then to obtain the energy associated, the force is multiplied by the laminate thickness $h$.

- linear momentum transfer: it is considered that the plug formed during the penetration is accelerated from the rest to the residual projectile velocity 
[10]; the corresponding equation is $0.5 m_{l} v_{r}^{2}$ where $m_{l}$ is the detached laminate which could be approximated as $\pi r^{2} h \rho_{l}$ being $h$ the laminate thickness and $\rho_{l}$ the laminate density.

The expression of the energy balance $E_{k}=E_{l m}+E_{p}$ could be finally written as follows:

$$
\frac{1}{2}\left(\frac{4}{3} \pi r^{3} \rho_{s}\right)\left(v_{i}^{2}-v_{r}^{2}\right)=\frac{1}{2} \pi r^{2} h \rho_{l} v_{r}^{2}+2 \pi r h^{2} \tau_{l}
$$

Rearranging terms, the residual velocity could be expressed as:

$$
v_{r}=\sqrt{\frac{4 r^{2} \rho_{s} v_{i}^{2}-12 h^{2} \tau_{l}}{3 r h \rho_{l}+4 r^{2} \rho_{s}}}
$$

In this expression it is easy to determine that keeping constant all the parameters, as $r$ increases the residual velocity increases also. Finally, in order to obtain the ballistic limit the residual velocity is set to zero and the following equation is obtained:

$$
v_{b l}=\sqrt{\frac{3 h^{2} \tau_{l}}{r^{2} \rho_{s}}}
$$

This simple equation shows that the relation between the ballistic limit and the projectile radius is $v_{b l} \propto 1 / r$, which means that as the radius $r$ increases, the ballistic limit decreases $v_{b l}$, and hence the penetration capacity grows. The increment of the mass with the radius has reveled to be more relevant than the distribution of the impact force along a wider area. Substituting the adequate values $\left(h=2.4 \mathrm{~mm}, \tau_{l}=100 \mathrm{MPa}\right.$ and $\left.\rho_{s}=7850 \mathrm{~kg} / \mathrm{m}^{3}\right)$ it is possible to obtain the ballistic limit for the analyzed projectile radius. Fig. 6 shows a comparison between the numerical and the analytical ballistic limits as function of the projectile radius; it is clear that the simple model reproduce 
accurately the values and hence is an adequate way to explain the influence of the projectile radius.

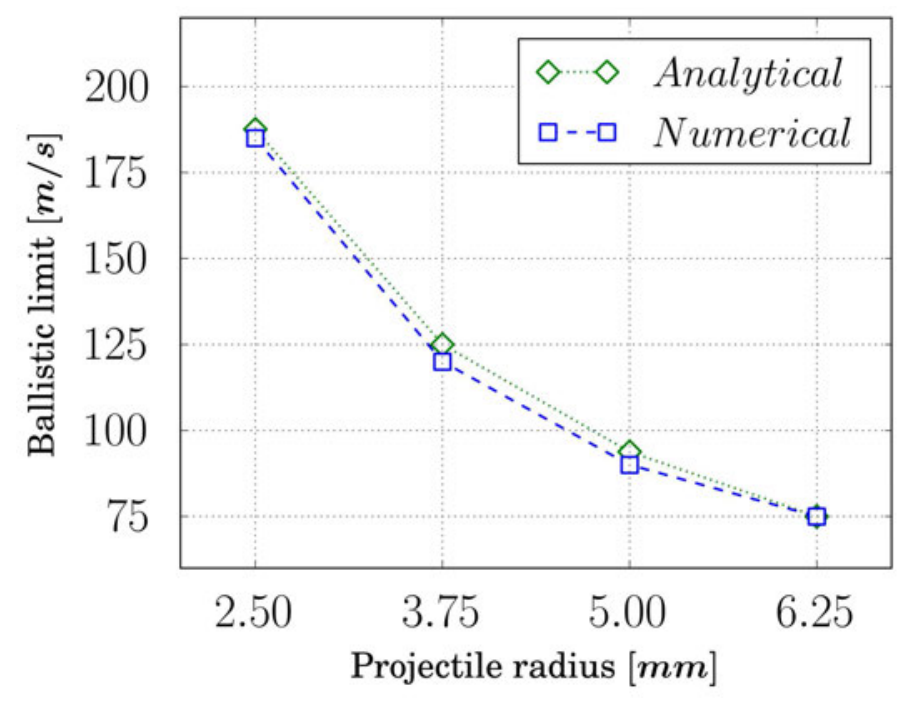

Fig. 6. Ballistic limit vs. projectile diameter.

\section{Conclusions}

In this work a numerical methodology has been proposed to predict the behaviour of unidirectional composite plates when impacted at high velocity by a steel sphere projectile. Once validated, the model has been used to analyze the influence of the sphere radius, and in addition a simple model has been proposed to explain the result obtained. The main conclusions are:

- To adequately model the behavior of composite laminates subjected to high velocity impacts it is necessary to use three dimensional models with one cohesive interaction for each inter ply. Other simplifications lead to a non adequate model of the damages that appear during the impact process.

- The projectile sphere radius affects significatively the impact process and hence the residual velocity. For a given impact velocity as the radius in- 
creases the residual velocity increases also.

- A simple analytical model, that uses an energy balance, has proven that the ballistic limit is proportional to the inverse of the square root of the projectile radius. The increment of mass due to the increment of radius becomes more relevant than the increase of affected area.

\section{Acknowledgements}

This research was done with the financial support of the Spanish Ministry of Education under Project reference DPI2010-15123 and of the Region of Madrid and University Carlos III of Madrid under Project reference CCG10UC3M/DPI-4694.

\section{References}

[1] Larsson F, Damage tolerance of a stitched carbon/epoxy laminate, Composites Part A: applied science and manufacturing 28 (1997) 923-934.

[2] Sun CT, Potti V, A simple model to predict residual velocities of thick composite laminates subjected to high velocity impact, International Journal of Impact Engineering 18(3) (1996) 339-353.

[3] Bland PW, Dear JP, Observations on the impact behaviour of carbon-fibre reinforced polymers for the qualitative validation of models, Composites Part A: applied science and manufacturing 32 (2001) 1217-1227.

[4] Will MA, Franz T, Nurick GN, The effect of laminate stacking sequence of CFRP filament wound tubes subjected to projectile impact, Composites Structures 58 (2002) 259-270. 
[5] López-Puente J, Zaera R, Navarro C, The effect of low temperatures on the intermediate and high velocity impact response of CFRP, Composites: Part B 33 (2002) 559-566.

[6] López-Puente J, Zaera R, Navarro C, High energy impact on woven laminates, Journal de Physique IV 110 (2003) 639-644.

[7] Tanabe Y, Aoki M, Fujii K, Kasano H, Yasuda E, Fracture behavior of cfrps impacted by relatively high-velocity steel sphere, International Journal of Impact Engineering 28 (2003) 627-642.

[8] Hosur MV, Vaidya UK, Ulven C, Jeelani S, Performance of stitched/unstitched woven carbon/epoxy composites under high velocity impact loading, Composite Structures 64 (2004) 455-466.

[9] Turon A, Camanho PP, Costa J, Dávila CJ, A damage model for the simulation of delamination in advanced composites under variable mode loading, Mechanics of Materials 38:11 (2006) 1072-1089.

[10] López-Puente J, Zaera R, Navarro C, An analytical model for high velocity impacts on thin cfrps woven laminates, International Journal of Solids and Structures 44 (2007) 2837-2851.

[11] Fernández-Fdz D, López-Puente J, Zaera R, Prediction of the behaviour of CFRPs against high-velocity impact of solids employing an artificial neural network methodology, Composites: Part A 39 (2008) 989-996.

[12] López-Puente J, Zaera R, Navarro C, Experimental and numerical analysis of normal and oblique ballistic impacts on thin carbon/epoxy woven laminates, Composites: Part A 39 (2008) 374-387.

[13] Garcia-Castillo, SK, Sanchez-Saez, S, López-Puente J, Barbero, E, Navarro, C, Impact behaviour of preloaded glass/polyester woven plates, Composites Science and Technology 69(6) (2009) 711-717. 
[14] López-Puente J, Varas D, Loya JA, Zaera R, Analytical modelling of high velocity impacts of cylindrical projectiles on carbon/epoxy laminates, Composites: Part A 40 (2009) 1223-1230.

[15] López-Puente J, Li S, Analysis of strain rate sensitivity of carbon/epoxy woven composites, International Journal of Impact Engineering 48 (2012) 54-64.

[16] Varas D, Artero-Guerrero JA,Pernas-Sánchez J, López-Puente J, Analysis of high velocity impacts of steel cylinders on thin carbon/epoxy woven laminates, Composite Structures 95 (2013) 623-629.

[17] Cantwell WJ, Morton J, An assessment of the impact performance of cfrp reinforced with high-strain carbon-fibers, Composites Science and Technology $25(2)$ (1986) 133-148.

[18] Cantwell WJ, Morton J, Comparison of low and high velocity impact response of CFRP, Composites 20(6) (1989) 545-551.

[19] Abrate S, Modeling of impacts on composite structures, Composite Structures 51(2) (2001) 129-138.

[20] Mines RAW, McKown S, Birch RS, Impact of aircraft rubber tyre fragments on aluminium alloy plates: I-experimental, International Journal of Impact Engineering 34 (2007) 627-646.

[21] Varas D, López-Puente J, Zaera R, Experimental analysis of fluid-filled aluminium tubes subjected to high-velocity impact, International Journal of Impact Engineering 36 (2009) 81-91.

[22] Varas D, Zaera R, López-Puente J, Numerical modelling of the hydrodynamic ram phenomenon, International Journal of Impact Engineering 36 (2009) 363374 .

[23] Varas D, López-Puente J, Zaera R, Numerical modelling of partially filled aircraft fuel tanks submitted to Hydrodynamic Ram, Aerospace Science and 
Technology 16 (2011) 19-28.

[24] Varas D, Zaera R, López-Puente J, Experimental study of CFRP fluid-filled tubes subjected to high-velocity impact, Composite Structures 93 (2011) 25982609.

[25] Varas D, López-Puente J, Zaera R, Numerical Analysis of the Hydrodynamic Ram Phenomenon in Aircraft Fuel Tanks, AIAA Journal 50 (2012) 1621-1630.

[26] Artero-Guerrero JA, Pernas-Sánchez J, Varas D, López-Puente J, Li S, Numerical analysis of CFRP fluid-filled tubes subjected to high-velocity impact, Composite Structures 96 (2013) 286-297.

[27] Khdeir AA, Reddy JN, An exact solution for the bending of thin and thick cross-ply laminated beams, Composite Structures 37(2) (1997) 195-203.

[28] Abrate S, The dynamics of impact on composite structures, Key Engineering Materials 143 (1998) 671-694.

[29] Hashin Z, Failure criteria for unidirectional fiber composites, Journal Applied Mechanics 47 (1980) 329-334.

[30] Chang FK, Chang KY, A progressive damage model for laminated composites containing stress concentrators, Journal of Composite Materials 21 (1987) 834.

[31] Hou J, Petrinic N, Ruiz C, A delamination criterion for laminated composites under low-velocity impact, Composite Science and Technology 61 (2001) 20692074 .

[32] Pinho ST, Dávila CG, Camanho PP, Iannucci L, Robinson P, Failure Models and Criteria for FRP Under In-Plane or Three-Dimensional Stress States Including Shear Non-Linearity, Research report, NASA/TM-2005-213530, NASA Langley Research Center, 2005. 
[33] Martinez X, Rastellini F, Oller S, Flores F, Oñate E, Computationally optimized formulation for the simulation of composite materials and delamination failures, Composites Part B: Engineering 42 (2011) 134-144.

[34] Prez MA, Martinez X, Oller S, Gil L, Rastellini F, Flores F, Impact damage prediction in carbon fiber-reinforced laminated composite using the matrixreinforced mixing theory, Composite Structures 104 (2013) 239-48.

[35] Hadavinia H, Ghasemnejad H, Effects of Mode-I and Mode-II interlaminar fracture toughness on the energy absorption of CFRP twill/weave composite box sections, Composite Structures 89 (2009) 303-314.

[36] Ghasemnejad H, Hadavinia H, Aboutorabi A, Effect of delamination failure in crashworthiness analysis of hybrid composite box structures, Materials \& Design 31 (2010) 1105-1116.

[37] Klaus M, Reimerdes HG, Gupta NK, Experimental and numerical investigations of residual strength after impact of sandwich panels, International Journal of Impact Engineering 44 (2012) 50-58.

[38] Hanh HT, Tsai S, On the Behavior of Composite Laminates After Initial Failures, Journal of Composite Materials 8 (1974) 288-305. 